\title{
(6) OPEN ACCESS \\ Targeted lung denervation for moderate to severe COPD: a pilot study
}

\author{
Dirk-Jan Slebos, ${ }^{1}$ Karin Klooster, ${ }^{1}$ Coenraad F N Koegelenberg, ${ }^{2}$ Johan Theron, ${ }^{3}$ \\ Dorothy Styen, ${ }^{2}$ Arschang Valipour, ${ }^{4}$ Martin Mayse, ${ }^{5}$ Chris T Bolliger ${ }^{2,3}$
}

${ }^{1}$ Department of Pulmonary diseases, University of Groningen, University Medical Center Groningen, Groningen, The Netherlands

${ }^{2}$ Faculty of Medicine and Health Sciences, Division of Pulmonology, Department of Medicine, Stellenbosch University, Cape Town, South Africa

${ }^{3}$ Medi Clinic Panorama, Cape Town, South Africa ${ }^{4}$ Department of Respiratory and Critical Care Medicine, Ludwig-Boltzmann-Institute for COPD and Respiratory Epidemiology, Otto-WagnerSpital, Vienna, Austria ${ }^{5}$ Holaira, Inc., Minneapolis, Minnesota, USA

\section{Correspondence to} Dr Dirk-Jan Slebos, University Medical Center Groningen, Department of Pulmonary diseases, AA11, PO Box 30001, Groningen 9700 RB The Netherlands; d.j.slebos@umcg.nl

Received 7 August 2014 Revised 9 February 2015 Accepted 12 February 2015 Published Online First 4 March 2015

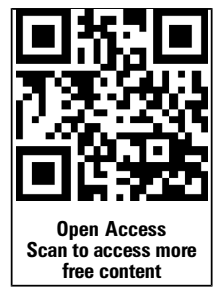

\section{CrossMark}

To cite: Slebos D-J,

Klooster K,

Koegelenberg CFN, et al.

Thorax 2015:70:411-419.

\section{ABSTRACT}

Background Parasympathetic pulmonary nerves release acetylcholine that induces smooth muscle constriction. Disruption of parasympathetic pulmonary nerves improves lung function and COPD symptoms.

Aims To evaluate 'targeted lung denervation' (TLD), a novel bronchoscopic therapy based on ablation of parasympathetic pulmonary nerves surrounding the main bronchi, as a potential therapy for COPD.

Methods This 1-year, prospective, multicentre study evaluated TLD in patients with COPD forced expiratory volume in $1 \mathrm{~s}\left(\mathrm{FEV}_{1}\right) /$ forced vital capacity (FVC) ( $\mathrm{FEV}_{1} /$ FVC <0.70; FEV $130 \%-60 \%$ predicted). Patients underwent staged TLD at 20 watts (W) or $15 \mathrm{~W}$ following baseline assessment off bronchodilators. Assessments were repeated on tiotropium before treatment and off bronchodilators at 30, 90, 180, 270 and 365 days after TLD. The primary endpoint was freedom from documented and sustained worsening of COPD directly attributable to TLD to 1 year. Secondary endpoints included technical feasibility, change in pulmonary function, exercise capacity, and quality of life. Results Twenty-two patients were included ( $n=12$ at $20 \mathrm{~W}, \mathrm{n}=10$ at $15 \mathrm{~W}$ ). The procedures were technically feasible $93 \%$ of the time. Primary safety endpoint was achieved in $95 \%$. Asymptomatic bronchial wall effects were observed in 3 patients at $20 \mathrm{~W}$. The clinical safety profiles were similar between the two energy doses. At 1 year, changes from baseline in the $20 \mathrm{~W}$ dose compared to the $15 \mathrm{~W}$ dose were: $\mathrm{FEV}_{1}(+11.6 \% \pm 32.3$ vs $+0.02 \% \pm 15.1, p=0.324)$, submaximal cycle endurance (+6.8 $\mathrm{min} \pm 12.8$ vs $2.6 \mathrm{~min} \pm 8.7, p=0.277$ ), and St George's Respiratory Questionnaire ( -11.1 points \pm 9.1 vs -0.9 points $\pm 8.6, p=0.044$ ).

Conclusions Bronchoscopic TLD, based on the concept of ablating parasympathetic pulmonary nerves, was feasible, safe, and well tolerated. Further investigation of this novel therapy is warranted.

Trial registration number NCT01483534.

\section{INTRODUCTION}

Cholinergic parasympathetic nerves innervate both large and small airways and provide the dominant innervation to human lungs. ${ }^{1}$ Acetylcholine released from these nerves regulates airway smooth muscle tone, mucus secretion, and potentially local inflammation through interaction with muscarinic receptors found throughout the bronchial tree. ${ }^{2} 3$ Furthermore, pulmonary parasympathetic activity is enhanced in COPD, and is the dominant reversible component of airway obstruction in this disease. ${ }^{2}$

\section{Key messages}

What is the key question?

- Parasympathetic pulmonary nerves release acetylcholine that causes smooth muscle contraction and increased mucus production contributing to airway obstruction and symptoms in COPD. Is bronchoscopic radiofrequency (RF) ablation of these pulmonary nerves safe and feasible in patients with mild to moderate COPD?

\section{What is the bottom line?}

- This first-in-human study evaluated bronchoscopic RF ablation of parasympathetic pulmonary nerves running along the main bronchi in patients with COPD. This approach is shown to be feasible and safe.

\section{Why read on?}

- This new bronchoscopic therapy called 'targeted lung denervation', is a potential future treatment option for patients with advanced COPD.

As such, disruption of parasympathetic activity in the lungs is a logical, well characterised, and an effective approach to the treatment of COPD.

Historically, parasympathetic nerve disruption via surgical vagotomy has consistently demonstrated the bronchodilator effect of vagotomy in animals. ${ }^{4}{ }^{5}$ Unfortunately, the majority of human research of vagotomy as a treatment for COPD is anecdotal or highly subjective. ${ }^{6}$ In one notable study, surgical denervation of the lungs in 19 patients with intractable bronchial asthma increased vital capacity from $2.36 \mathrm{~L}$ to $2.79 \mathrm{~L}$, and maximal voluntary ventilation from $43 \mathrm{~L}$ to $50 \mathrm{~L} / \mathrm{min}^{7}$. Sputum production was essentially stopped in eight of the 11 patients with a previous history of heavy sputum production.

In more recent history, pharmacologic blockade of acetylcholine binding to muscarinic receptors has been shown to produce bronchodilation and decrease mucous production. ${ }^{8}$ One trial in COPD demonstrated tiotropium to have a $9.6 \%$ improvement in trough-forced expiratory volume in $1 \mathrm{~s}\left(\mathrm{FEV}_{1}\right)$ at 1 year accompanied by a -4.5 -point change in $\mathrm{St}$ George's Respiratory Questionnaire (SGRQ). ${ }^{9}$ Similar improvements in lung function and health-related quality-of-life (HRQL) have been demonstrated by 
others. $^{10} 11$ Tiotropium, when compared with placebo, also improves cycle endurance time by $3.9 \mathrm{~min}, 2.5 \mathrm{~h}$ after inhalation, and $2.9 \mathrm{~min}, 8 \mathrm{~h}$ after inhalation. ${ }^{12}$ A significant focus on drug development has resulted in numerous pharmaceutical therapies to help manage COPD, and the majority of today's treatment guidelines recommend anticholinergics as first-line therapy for patients with mild to advanced stages of COPD. ${ }^{13} 14$

\section{Targeted lung denervation}

Targeted lung denervation (TLD) is a novel bronchoscopic therapy that ablates the parasympathetic innervation of the lungs, and has a similar proposed mechanism of action to anticholinergic drugs. ${ }^{2}$ TLD therapy is delivered via a dual-cooled radiofrequency (RF) catheter (Holaira, Minneapolis, Minnesota, USA) (figure 1) designed to target tissue heating at depth, thereby producing a narrow band of ablation around the main bronchi while minimising effects to the inner surface of the airway. As RF current passes from the electrode through the airway and surrounding tissues, these tissues are heated. Coolant continuously circulated through the electrode and balloon removes heat from the surface of the airway wall. The net effect is targeted tissue ablation at depth with minimal heating and damage of the inner surface of the airway.

This targeted tissue ablation is intended to disrupt motor axons within bronchial nerve branches running along the outside of the main bronchi, thereby blocking parasympathetic signalling to the lungs and decreasing neuronal release of acetylcholine. This decrease in acetylcholine reduces airway obstruction in the whole lung by decreasing smooth muscle tone and mucous production.

Extensive animal and human cadaver testing was undertaken to develop the system and determine initial therapeutic RF energy levels (unpublished data). This first-in-human study was designed to investigate the safety and feasibility of TLD therapy in patients with moderate to severe COPD.

\section{METHODS}

\section{Study design and participants}

This non-randomised, prospective, sequential, two-dose study was conducted at two sites in South Africa and one in The Netherlands between 31 October 2011 and 21 November 2013. Eligible patients were $\geq 40$ years of age with COPD; defined as the ratio of the forced expiratory volume in $1 \mathrm{~s}\left(\mathrm{FEV}_{1}\right)$ to the forced vital capacity (FVC) of $\leq 0.70$ and postbronchodilator $\mathrm{FEV}_{1}$ of $30 \%-60 \%$ of predicted normal values. Only patients with a $15 \%$ or greater relative increase in $\mathrm{FEV}_{1}$ following inhalation of $80 \mu \mathrm{g}$ ipratropium bromide were included.



Figure 1 Description of the key components of the targeted lung denervation (TLD) catheter.

\section{Box 1 Protocol Inclusion and Exclusion Criteria}

Inclusion criteria

- $\mathrm{FEV}_{1} 30 \%-60 \%$

- $\mathrm{FEV}_{1} / \mathrm{FVC}<70 \%$

- Patient is diagnosed with COPD $\left(\mathrm{FEV}_{1} / \mathrm{FVC}<70 \%\right)$

- Positive relative change in $\mathrm{FEV}_{1}>15 \%$ following administration of ipratropium

- $\geq 40$ years of age or older

- Smoking history of at least 10 pack years

- Non-smoking for a minimum of 6 months before consent and agreed to continue not smoking for the duration of the study

- Patient has provided written informed consent

- The patient is willing, able and agrees to complete all protocol-required baseline and follow-up assessments including taking and abstaining from medications

- The patient has no child-bearing potential or a negative pregnancy test

- Patient is a candidate for bronchoscopy in the opinion of the physician or per hospital guidelines

- Current influenza vaccination and/or pneumococcus vaccination consistent with local recommendations and/or policy

Exclusion criteria

- Pulmonary hypertension, peripheral oedema suggesting CHF or polycythaemia

- Patient has an $\mathrm{SaO} 2 \leq 88 \%$ or a PaO2 $\leq 7.3 \mathrm{kPa}(55 \mathrm{~mm} \mathrm{Hg})$

- Patient has a PaCO2 > $8.0 \mathrm{kPa}(60 \mathrm{~mm} \mathrm{Hg})$

- Previous lung transplant, LVRS, median sternotomy, bullectomy or lobectomy

- Pulmonary nodule requiring surgery

- History of recurrent respiratory infections (>3 hospitalisations within 1 year of consent)

- Presence of a pacemaker, internal defibrillator or other implantable electronic devices

- Active respiratory infection within the past 4 weeks

- COPD exacerbation within the past 4 weeks

- Myocardial infarction within the last 6 months

- Unstable or life-threatening arrhythmia within the last year

- Malignancy treated with radiation or chemotherapy within the last 2 years

- Presence of other respiratory diseases (cystic fibrosis, tuberculosis, vocal cord dysfunction, Churg-Strauss syndrome, allergic bronchopulmonary aspergillosis)

- Known hypersensitivity to anticholinergic drugs or components

- Known allergy to medications required for bronchoscopy (such as lidocaine, atropine) that cannot be medically controlled

- Clinical diagnosis of sleep apnoea

- Clinical diagnosis of asthma or other respiratory disease other than COPD

- Known coagulopathy

- Patient is taking clopidogrel, coumadin or other blood-thinning medication

- The patient has any disease or condition that might interfere with completion of this study (eg, life expectancy less than 1 year)

- Patient is currently enrolled in another clinical trial CHF, congestive heart failure; LVRS, lung volume reduction surgery; $\mathrm{PaO}_{2}$, partial pressure of oxygen; $\mathrm{SaO}_{2}$, saturation of oxygen. 
Key exclusion criteria included: COPD exacerbation or active respiratory infection within the past 4 weeks, more than 3 respiratory-related hospitalisations within 1 year of enrolment, previous lung surgery, suspicious pulmonary nodule, pulmonary hypertension, congestive heart failure, polycythaemia, $\mathrm{SaO}_{2}$ $\leq 88 \%$ or a $\mathrm{PaO} 2 \leq 7.3 \mathrm{kPa}$, and $\mathrm{PaCO}_{2}>8.0 \mathrm{kPa}$. Formal pulmonary rehabilitation was not a requirement for inclusion. Refer to the box 1 for a full list of inclusion and exclusion criteria.

This study was approved by local ethics committees and in accordance with the Declaration of Helsinki (1996), Good Clinical Practice guidelines, and local requirements. An operations committee, and a data monitoring committee, oversaw protocol management and safety for the study. An independent clinical event reviewer adjudicated all serious adverse events (SAE). This trial is registered with ClinicalTrials.gov, number NCT01483534.

\section{Study endpoints}

The primary safety endpoint of freedom from documented and sustained worsening of COPD directly attributable to the investigational device or procedure to a 365 -days post-TLD therapy, was defined as a decrease in the individual patient's $\mathrm{FEV}_{1}$ by any amount at all follow-up time points, along with a report of an adverse event that was reported to have a probable or definite relation to the device. Secondary endpoints included technical feasibility of the device and change from baseline in pulmonary function tests, exercise capacity assessments, and HRQL. Technical feasibility was defined as the ability to access the target treatment area main bronchus and deliver RF energy to the entire circumference of the bronchus at the target treatment site.

\section{Procedures}

After informed consent, patients underwent baseline testing after a wash-out period of 8 days for long-acting muscarinic antagonists (LAMA), $24 \mathrm{~h}$ for long-acting $\beta$ agonists (LABA) and $12 \mathrm{~h}$ for short-acting $\beta$ agonists (SABA) and short-acting muscarinic antagonists (SAMA). Baseline and follow-up testing included spirometry, body plethysmography, cycle ergometry, 6 min walk test (6MWT), COPD-specific SGRQ (score range 0-100 with a minimally clinically important difference (MCID) of $\geq 4$ negative units ${ }^{15}$ ), the Clinical COPD Questionnaire (CCQ, 7-day version, score range $0-6$, with an MCID of 0.4 units $\left.^{16}\right)$, the common Borg and modified Medical Research Council ${ }^{17}$ scales. Cycle ergometry was first conducted as an incremental maximal test to determine baseline maximum work rate $\left(\mathrm{W}_{\max }\right)$ off drugs, and subsequently as an endurance test conducted at a constant work rate of $75 \%$ of the $\mathrm{W}_{\max }{ }^{18}$ Current American Thoracic Society (ATS)/European Respiratory Society (ERS) guidelines were followed for pulmonary function testing, ${ }^{19} 20$ and ATS/American College of Chest Physicians (ACCP) guidelines for cycle ergometry $^{21}$ and the $6 \mathrm{MWT}^{22} \mathrm{~A}$ baseline chest CT scan was required to confirm appropriate bronchial anatomy and rule out other pulmonary abnormalities.

After completion of the wash-out baseline testing, patients underwent a minimum 8-day run-in period while on tiotropium bromide, and similar testing was performed at drug trough $24 \mathrm{~h}$ after the last dose of tiotropium to establish tiotropium trough baseline values. LABAs were again held for $24 \mathrm{~h}$ and SABAs and SAMAs for $12 \mathrm{~h}$ before this testing. All patients underwent early safety evaluation by phone at 3 days and 10 days postprocedure. Testing was repeated at washout baseline, tiotropium trough baseline, and 30, 90, 180, 270 and 365 days post-treatment, except for cycle ergometry which was performed at 90, 180 and 365 days post-treatment. Patients were provided a daily memory aid to track overall changes in health status. A total of three bronchoscopies were performed per patient; two in order to complete the two treatments and the third one to assess potential airway surface effects during the 90-day follow-up visit. Adverse events were tracked and recorded throughout the entire study period.

\section{Treatment}

Pretreatment visual bronchoscopic inspection of the airways was conducted to reconfirm that appropriate airway anatomy existed. Due to the construction of this first-generation device, procedures were performed via rigid bronchoscopy under general anaesthesia. The dual-cooled catheter was placed through the rigid bronchoscope, and a flexible bronchoscope placed beside it for visualisation. The electrode was placed and activated in up to eight rotational positions per bronchus to achieve complete circumferential treatment. Total balloon inflation times were approximately $3 \mathrm{~min}$ per activation. The initial subjects were treated with 20 watts (W) in all positions except for the posterior-medial aspects of the left bronchus, where the power was reduced to $15 \mathrm{~W}$ due to the proximity of the oesophagus in those positions. Due to local airway effects, after a protocol amendment, additional patients underwent treatment with a more distal placement of the electrode along the medial wall to avoid the thin tissue of the carina, and a lower $15 \mathrm{~W}$ energy level in all position. Bronchoscopic and fluoroscopic visualisation was used to guide the electrode positioning (figure 2) throughout treatment. To maximise safety, the protocol mandated staged treatment ( 2 therapeutic procedures per patient) with the second bronchus being treated 30 days after the first. No special post procedure medications were required, and the use of tiotropium was stopped. Investigators were allowed to treat respiratory symptoms per

Figure 2 ( $A$ and $B$ ) fluoroscopic view (A) and bronchoscopic view (B) of the electrode during the procedure. The electrode is indicated by the arrow.

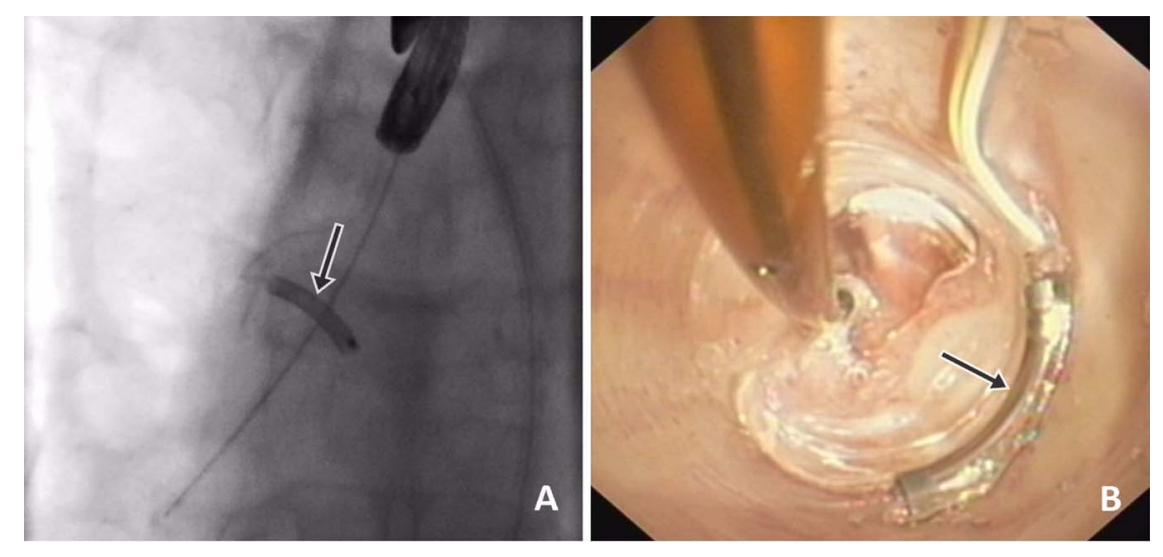




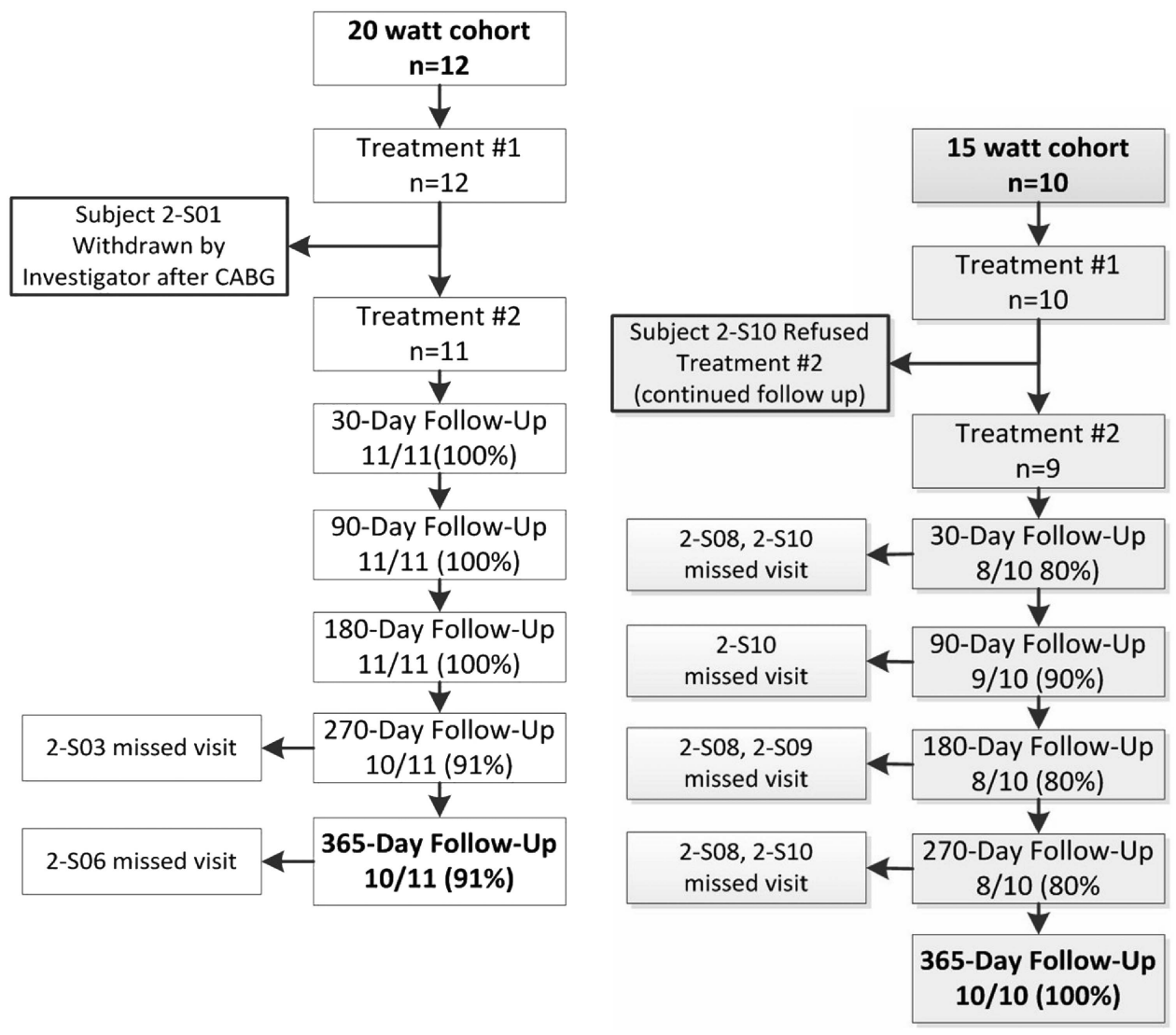

Figure 3 Clinical trial profile and patient flowchart.

standard-of-care and published guidelines, however, appropriate drug wash-out was required before follow-up testing.

\section{Statistical methods}

As this was a feasibility study, there was no primary study hypothesis with statistical inference. All $\mathrm{p}$ values were presented for informational purposes. According to the prespecified analysis plan, continuous data were summarised using means and SDs, or medians and quartiles, in the presence of non-normality.
Categorical data were tabulated, with counts and percentages. All available data was summarised, with no imputation for missing data. Final analyses were conducted using SAS V.9.3 (SAS Institute, Cary, North Carolina, USA) by an independent statistical group (NAMSA, Minneapolis, Minnesota, USA).

\section{Role of the funding source}

The sponsor, D-JS, MM and CB designed the trial. Sites recruited patients and collected data on standardised case report

Table 1 Baseline characteristics. Data are mean (SD) unless stated otherwise

\begin{tabular}{|c|c|c|c|}
\hline & 20 W cohort $(n=12)$ & 15 W cohort $(n=10)$ & p Value \\
\hline Age (years) & $62.92(11.37)$ & $64.40(8.87)$ & 0.740 \\
\hline Male $(n, \%)$ & $7(58)$ & $4(40)$ & 0.669 \\
\hline \multicolumn{4}{|l|}{ Ethnic origin (n, \%) } \\
\hline White & $12(100)$ & $8(80)$ & 0.195 \\
\hline Black & $0(0)$ & $2(20)$ & - \\
\hline History of smoking (n, \%) & $12(100)$ & $10(100)$ & - \\
\hline Pack-years & 38.57 (19.97) & $44.60(25.86)$ & 0.544 \\
\hline Wash-out prebronchodilator $\mathrm{FEV}_{1}$ (L) & $0.90(0.28)$ & $0.84(0.15)$ & 0.551 \\
\hline Wash-out prebronchodilator FVC (L) & $2.56(0.59)$ & $2.45(0.60)$ & 0.664 \\
\hline Reversibility peak relative change in $\mathrm{FEV}_{1}(\%)$ & $25.95(7.60)$ & $19.89(1.91)$ & 0.019 \\
\hline Run-in tiotropium trough $\mathrm{FEV}_{1}(\mathrm{~L})$ & $1.04(0.39)$ & $0.98(0.23)$ & 0.651 \\
\hline Run-in tiotropium trough FVC (L) & $2.89(0.76)$ & $2.75(0.60)$ & 0.661 \\
\hline Cycle endurance time @ 75\% of max (min) & $6.71(3.26)$ & $4.57(2.20)$ & 0.1059 \\
\hline SGRQ-C total score (points) & $56.16(13.71)$ & $56.23(20.85)$ & 0.9931 \\
\hline Average diameter: right main bronchus $(\mathrm{mm})^{*}$ & $13.42(1.57)$ & $13.91(1.62)$ & 0.519 \\
\hline Average diameter: left main bronchus $(\mathrm{mm})^{*}$ & $12.02(1.45)$ & $12.33(1.68)$ & 0.672 \\
\hline
\end{tabular}


Table 2 Summary of adverse events through 1 year

\begin{tabular}{|c|c|c|c|c|c|c|}
\hline \multirow[b]{2}{*}{$\begin{array}{l}\text { RF dosage, watt } \\
\text { Adverse event } \\
\end{array}$} & \multicolumn{2}{|l|}{$\begin{array}{l}20 \text { watt cohort } \\
n=12\end{array}$} & \multicolumn{2}{|l|}{$\begin{array}{l}15 \text { watt cohort } \\
n=10\end{array}$} & \multicolumn{2}{|l|}{$\begin{array}{l}\text { All } \\
n=22\end{array}$} \\
\hline & $\begin{array}{l}\text { Adverse event } \\
\text { frequency } \\
n=60(\%)\end{array}$ & $\begin{array}{l}\text { Subject * } \\
\text { frequency } \\
(\%)\end{array}$ & $\begin{array}{l}\text { Adverse event } \\
\text { frequency } \\
n=39(\%)\end{array}$ & $\begin{array}{l}\text { Subject* } \\
\text { frequency } \\
(\%)\end{array}$ & $\begin{array}{l}\text { Adverse event } \\
\text { frequency } \\
n=99(\%)\end{array}$ & $\begin{array}{l}\text { Subject* } \\
\text { frequency } \\
(\%)\end{array}$ \\
\hline \multicolumn{7}{|l|}{ Device-related non-serious } \\
\hline Bronchial perforation (carina) & $2(3)$ & $2(17)$ & - & - & $2(2)$ & $2(9)$ \\
\hline Bronchial stenosis & $1(2)$ & $1(8)$ & - & - & $1(1)$ & $1(5)$ \\
\hline Bronchial ulceration & $1(2)$ & $1(8)$ & - & - & $1(1)$ & $1(5)$ \\
\hline COPD Exacerbation & - & - & $1(3)$ & $1(10)$ & $1(1)$ & $1(5)$ \\
\hline Granulomas & $1(2)$ & $1(8)$ & - & - & $1(1)$ & $1(5)$ \\
\hline Worsening of $\mathrm{FEV}_{1} \dagger$ & - & - & $1(3)$ & $1(10)$ & $1(1)$ & $1(5)$ \\
\hline \multicolumn{7}{|l|}{ Device related-serious } \\
\hline Gastroparesis & - & - & $1(3)$ & $1(10)$ & $1(1)$ & 1 (5) \\
\hline \multicolumn{7}{|c|}{ Procedural related-non-serious (related or reported within 2 days of either procedure) } \\
\hline Broken tooth & $1(2)$ & $1(8)$ & & & $1(1)$ & $1(5)$ \\
\hline Cough & $2(3)$ & $2(17)$ & - & - & $2(2)$ & $2(9)$ \\
\hline Dyspnoea & $2(3)$ & $2(17)$ & $1(3)$ & $1(10)$ & $3(3)$ & $3(14)$ \\
\hline Eczema & - & - & $1(3)$ & $1(10)$ & $1(1)$ & $1(5)$ \\
\hline Headache & $2(3)$ & $2(17)$ & - & - & $2(2)$ & $2(9)$ \\
\hline Mucus & $3(5)$ & $3(25)$ & - & - & $3(3)$ & $3(14)$ \\
\hline Sore throat & $3(5)$ & $3(25)$ & $1(3)$ & $1(10)$ & $4(4)$ & $4(18)$ \\
\hline $\begin{array}{l}\text { Tracheal injury (due to rigid } \\
\text { bronchoscope) }\end{array}$ & $1(2)$ & $1(8)$ & - & - & $1(1)$ & $1(5)$ \\
\hline \multicolumn{7}{|c|}{ Procedural related-serious (related or reported within 2 days of either procedure) } \\
\hline Anaphylactic reaction & $1(2)$ & $1(8)$ & - & - & $1(1)$ & $1(5)$ \\
\hline COPD exacerbation & - & - & $1(3)$ & $1(10)$ & $1(1)$ & $1(5)$ \\
\hline \multicolumn{7}{|l|}{ Other non-serious } \\
\hline Abscess (skin) & - & - & $1(3)$ & $1(10)$ & $1(1)$ & $1(5)$ \\
\hline Back ache & $1(2)$ & $1(8)$ & - & - & $1(1)$ & 1 (5) \\
\hline Bronchitis & - & - & $5(13)$ & $2(20)$ & $5(5)$ & $2(9)$ \\
\hline Candida & - & - & $1(3)$ & $1(10)$ & $1(1)$ & $1(5)$ \\
\hline Chest pain & $1(2)$ & $1(8)$ & - & - & $1(1)$ & $1(5)$ \\
\hline Common cold & $2(3)$ & $2(17)$ & - & - & $2(2)$ & $2(9)$ \\
\hline COPD exacerbation & $12(20)$ & $7(58)$ & $13(33)$ & $6(60)$ & $25(25)$ & $13(59)$ \\
\hline Cough & $1(2)$ & $1(8)$ & - & - & $1(1)$ & $1(5)$ \\
\hline Diarrhoea & $1(2)$ & $1(8)$ & - & - & $1(1)$ & 1 (5) \\
\hline Difficulty swallowing & $1(2)$ & $1(8)$ & - & - & $1(1)$ & 1 (5) \\
\hline Dizziness & $2(3)$ & $2(17)$ & $1(3)$ & $1(10)$ & $3(3)$ & $3(14)$ \\
\hline Dyspnoea & $3(5)$ & $2(17)$ & $1(3)$ & $1(10)$ & $4(4)$ & $3(14)$ \\
\hline Flu & $3(5)$ & $3(25)$ & $1(3)$ & $1(10)$ & $4(4)$ & $4(18)$ \\
\hline Gastritis & $2(3)$ & $2(17)$ & $1(3)$ & $1(10)$ & $3(3)$ & $3(14)$ \\
\hline Gastroparesis & $1(2)$ & $1(8)$ & - & - & $1(1)$ & $1(5)$ \\
\hline Pneumonia & $1(1)$ & $1(8)$ & - & - & $1(1)$ & $1(5)$ \\
\hline Respiratory inflammation & $4(7)$ & $4(33)$ & - & - & $4(4)$ & $4(18)$ \\
\hline Sinusitis & - & - & $1(3)$ & $1(10)$ & $1(1)$ & $1(5)$ \\
\hline \multicolumn{7}{|l|}{ Other serious } \\
\hline Chest pain & - & - & $1(3)$ & $1(10)$ & $1(1)$ & $1(5)$ \\
\hline COPD exacerbation & $2(3)$ & $2(17)$ & $5(13)$ & $3(30)$ & $7(7)$ & $5(23)$ \\
\hline Coronary artery disease/CABG & $1(2)$ & - & - & - & $1(1)$ & $1(5)$ \\
\hline Flu & - & - & $1(3)$ & $1(10)$ & $1(1)$ & $1(5)$ \\
\hline Lung infection & $2(3)$ & $2(17)$ & - & - & $2(2)$ & $2(9)$ \\
\hline Stomach cancer (stage 3) & - & - & $1(3)$ & $1(10)$ & $1(1)$ & $1(5)$ \\
\hline
\end{tabular}




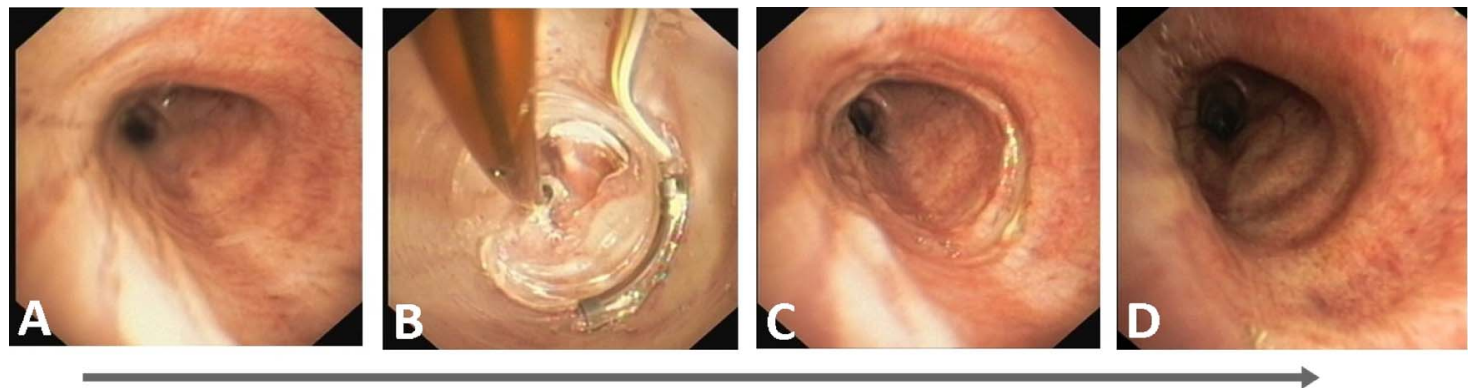

Figure 4 Bronchoscopic confirmation of airway healing after radiofrequency energy delivery: (A) Left main bronchus pretreatment. (B) During treatment. (C) Immediately post-treatment. (D) 3-month follow-up.

forms. The sponsor managed the overall study and safety committees.

\section{RESULTS}

Twelve patients were included in the $20 \mathrm{~W}$ cohort, and an additional 10 patients were included as part of the $15 \mathrm{~W}$ cohort at the same sites using the same study criteria (figure 3). Demographic and baseline characteristics were similar between the two cohorts, with the $15 \mathrm{~W}$ cohort enrolling patients with slightly worse baseline $\mathrm{FEV}_{1}$ (table 1). One-year follow-up data were available in 10 of 11 available patients in the $20 \mathrm{~W}$ cohort, and all 10 of the $15 \mathrm{~W}$ cohort. One patient in the $20 \mathrm{~W}$ cohort underwent coronary bypass surgery for a calcified coronary lesion during follow-up, and was withdrawn from the study by the site investigator before the
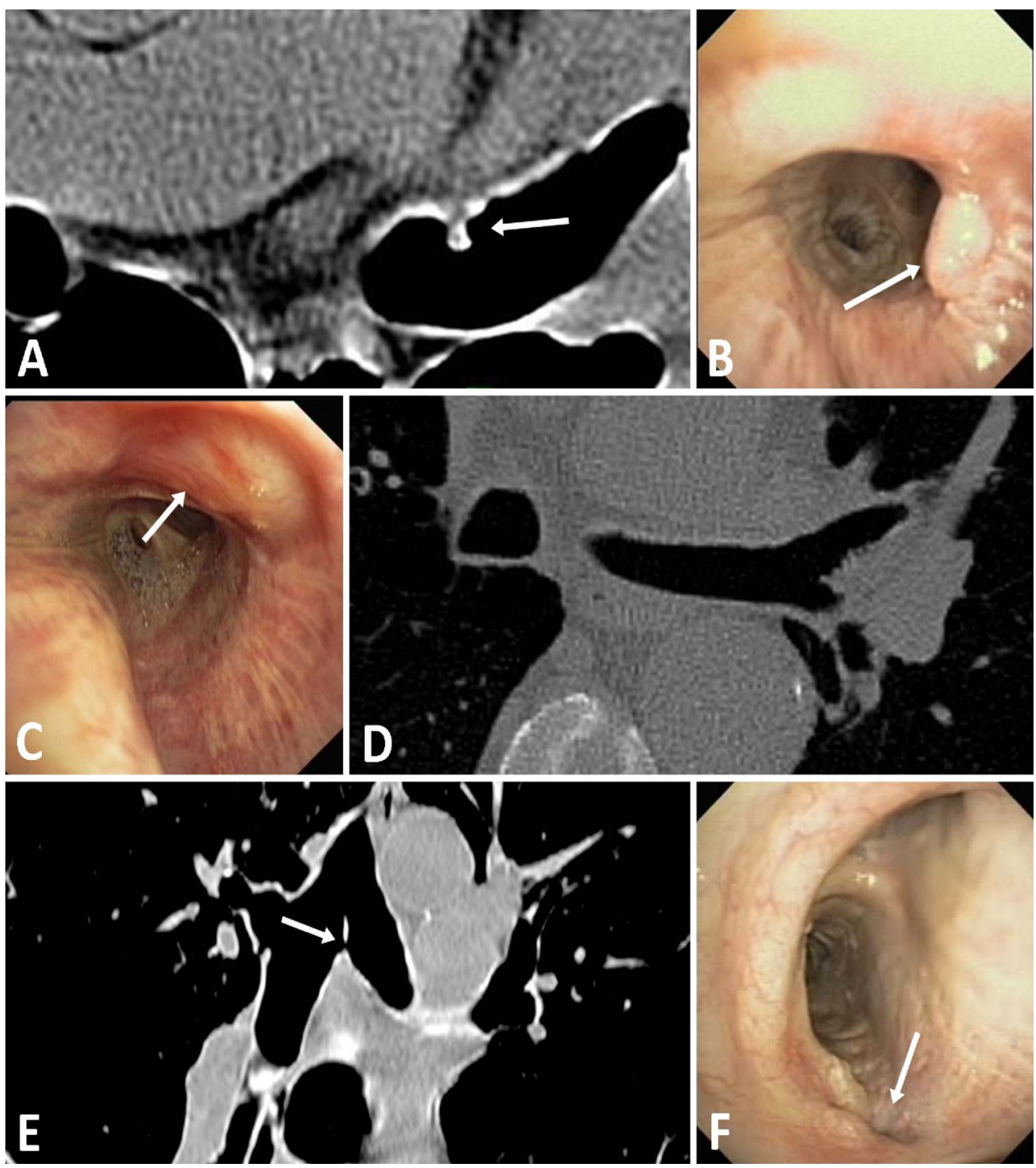

Figure $5 \mathrm{CT}$ and bronchoscopic findings seen before procedural enhancements: (A and B) A $4 \mathrm{~mm}$ granuloma indicated by white arrows on both transverse $C T$ and bronchoscopic images. (C and D) Superficial airway effect indicated by white arrow on the bronchoscopic image with normal transverse CT image. (E and F) A $1.5 \mathrm{~mm}$ perforation through carina indicated by white arrows on both coronal CT and bronchoscopic images. 

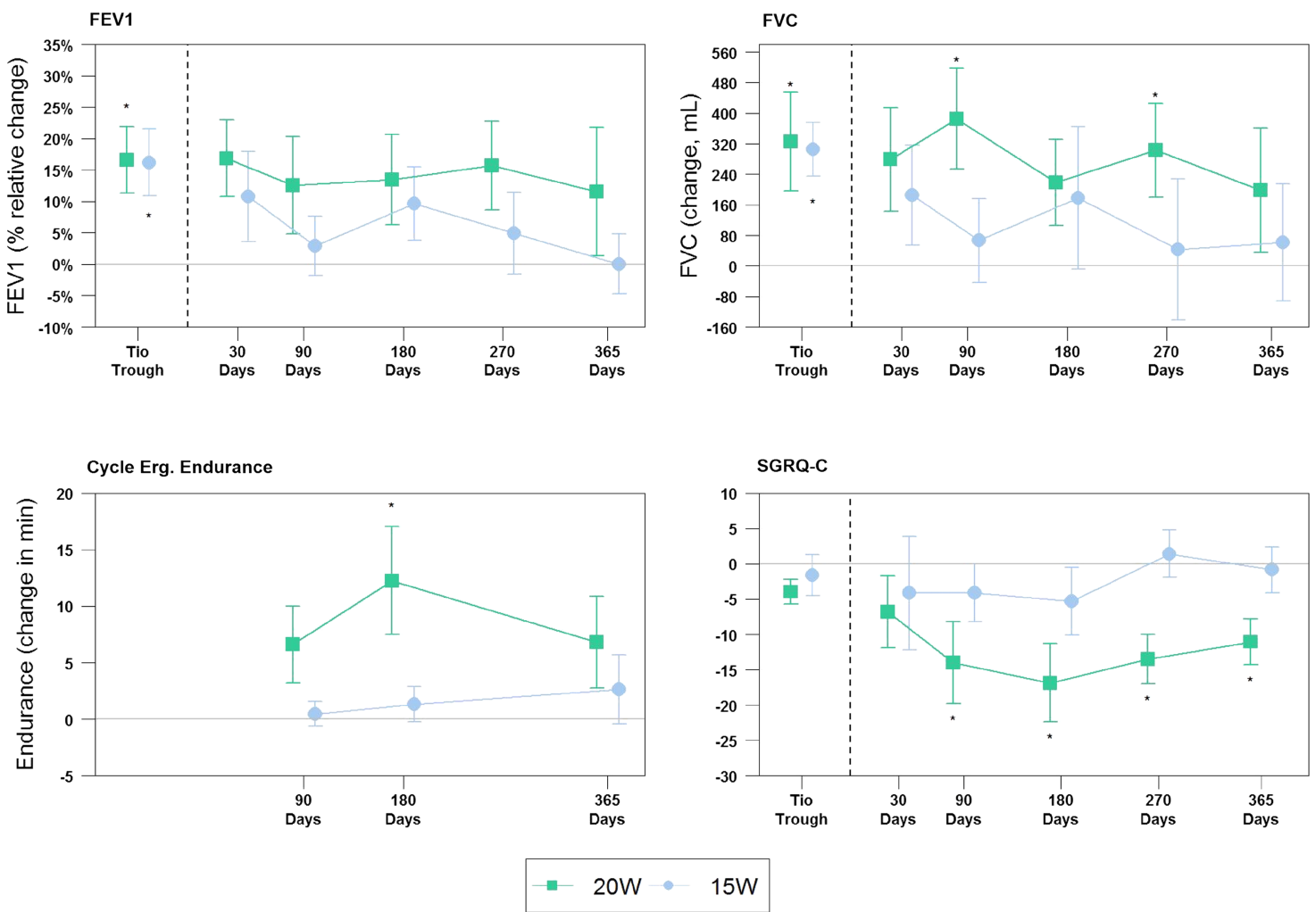

Figure 6 Secondary efficacy endpoints. Data represented as mean. Error bars represent SEM. * $p<0.05$ compared with baseline; FEV ${ }_{1}$ : forced expiratory volume in $1 \mathrm{~s}$; Cycle Erg. Endurance, Cycle Ergometry Endurance; SGRQ, St. George's Respiratory Questionnaire.

second procedure. One patient in the $15 \mathrm{~W}$ cohort experienced a COPD exacerbation 10 days after the initial procedure and did not consent to the 2 nd treatment, but continued follow-up.

The primary safety endpoint was achieved in $100 \%(11 / 11)$ in the $20 \mathrm{~W}$ cohort and $90 \%(9 / 10)$ in the $15 \mathrm{~W}$ cohort. The one subject that failed to meet the endpoint had a decrease from baseline in $\mathrm{FEV}_{1}$ at all follow-up time points, and a COPD exacerbation 1 day after the 2 nd treatment that was reported as related to the lung denervation system and/or the bronchoscopy by the investigator.

No deaths occurred in this study. Seven postprocedure SAEs in the 30 days following treatment of either bronchus included COPD exacerbation $(n=3)$, anaphylactic drug reaction, coronary artery bypass surgery, chest pain resulting in uneventful hospitalisation, and gastroparesis in a subject with a history of gastric issues. Four of these seven events occurred in a single patient. Nine longer-term SAEs out to 1 year included COPD exacerbation $(n=5)$, pneumonia $(n=2)$, influenza (H1N1) $(n=1)$, and stomach cancer $(n=1)$. Events were evenly distributed between both cohorts, with the majority of events reported during the periprocedural period (table 2).

The RF energy applied to the airway wall resulted in local asymptomatic airway blanching, which resolved at the 3-month follow-up bronchoscopy in all 10 of the $15 \mathrm{~W}$ patients, and in eight of the $11 \mathrm{~W}-20 \mathrm{~W}$ patients with long-term follow-up (figure 4). One patient had a superficial tissue defect at the first treatment site seen at 30 days, without any airway abnormalities on CT. A second patient had a small $1.5 \mathrm{~mm}$ perforation through the thin tissue of the main carina, also discovered at 30 days. A third patient had a superficial tissue defect at the initial treatment site just distal to the main carina, as well as a $4 \mathrm{~mm}$ granuloma at the second treatment site, with a $20 \%$ stenosis observed during the follow-up bronchoscopy at 90 days (figure 5). The granuloma was electively removed by cauterisation. No other treatments or interventions were performed, and all showed complete or active healing during follow-up visual inspection.

Technical feasibility was 93\%, with 39 of 42 procedures delivering full circumferential treatment (up to eight individual activations) to the target treatment site of the main bronchus. Two patients had only one bronchus treated as outlined above. Three patients had incomplete (non-circumferential) treatment: two had airway geometries that limited electrode/balloon contact with the right mainstem bronchus wall, and one had an intraprocedural anaphylactic reaction to diclofenac that prohibited full left bronchus treatment.

No device-related adverse events occurred during the procedure. Mean (SD) procedure time (min) for the $20 \mathrm{~W}$ cohort was $47.75 \pm 8.13$ for the right and $56.10 \pm 12.79$ for the left bronchi. Mean procedure time for the $15 \mathrm{~W}$ cohort was $42.10 \pm 8.23$ for the right and $51.33 \pm 25.76$ for the left.

The results of $\mathrm{FEV}_{1}$ (\% relative change), FVC, cycle ergometry endurance and SGRQ at each time point assessed are shown in figure 6. At the higher $20 \mathrm{~W}$ power level, significant differences from baseline were seen at the following assessment time points: FVC at 90 days $(p=0.016)$ and 270 days $(p=0.036)$; cycle endurance at 180 days $(\mathrm{p}=0.03)$, and SGRQ at 90 days $(\mathrm{p}=0.042)$, 180 days $(p=0.019), 270$ days $(p=0.008)$ and 1 year $(p=0.011)$. Variability across time is noted, and most likely due to the small sample size. No statistically significant differences in any of the variables measured were seen at the $15 \mathrm{~W}$ power level.

$\mathrm{FEV}_{1}$ per cent change from baseline at 1 year was $11.6 \pm 32.3 \%$ vs $0.02 \pm 15.1 \%(p=0.324)$ in the $20 \mathrm{~W}$ and $15 \mathrm{~W}$ cohorts, respectively (table 3 ). Similarly, FVC had a positive absolute positive change in FVC at 1 year of $198 \pm 516 \mathrm{~mL}$ in the $20 \mathrm{~W}$ cohort vs $61 \pm 485 \mathrm{~mL}(\mathrm{p}=0.256)$ in the $15 \mathrm{~W}$ cohort (figure 6). 
Table 3 Comparison of outcomes at 1 year for patients with follow-up testing

\begin{tabular}{lllll}
\hline Outcome & $\begin{array}{l}20 \text { watt cohort } \\
(n=10)\end{array}$ & $\begin{array}{l}15 \text { watt cohort } \\
(n=10)\end{array}$ & $\begin{array}{l}\text { Overall } \\
(n=20)\end{array}$ & $p$ Value \\
\hline
\end{tabular}

$\mathrm{FEV}_{1}(\mathrm{~mL})$

Baseline

$851.0(277.3)$

$836.0(148.0)$

1 year

$900.0(268.6)$

$835.0(185.5)$

$843.5(216.5) \quad 0.882$

Per cent $\Delta$

$11.6(32.3)$

$0.02(151)$

867.5 (227.1) $\quad 0.537$

FVC ( $\mathrm{mL})$

Baseline $\quad 2439.0(538.2)$

$2448.0(602.9)$

1 year

$2637.0(802.2)$

$2509.0(665.6)$

Per cent $\Delta \quad 7.6(21.9)$

$39(19.1)$

Total lung capacity (TLC)

Baseline

$7.2(1.2)$

1 year

$7.3(1.8)$

$6.8(1.2)$

$7.2(1.2)$

$5.2(9.6)$

Per cent $\Delta$

$1.0(11.8)$

Residual volume (RV)

$4.6(0.7)$

1 year

$4.6(1.2)$

$4.1(0.7)$

$4.4(0.9)$

$7.9(20.6)$

$5.8(25.3) \quad 0.324$

Percent $\Delta \quad 0.5(21.2)$

Inspiratory capacity (IC)

$1.8(0.5)$

1 year

$1.7(0.78)$

$1.7(0.6)$

$1.8(0.6)$

$7.3(22.0)$

2443.5 (556.3) 0.972

$2573.0(720.4) \quad 0.702$

$5.7(20.1) \quad 0.690$

Percent $\Delta \quad-2.0$ (31.6)

Pulmonary resistance $(\mathrm{kPaxs} / \mathrm{L})$

$0.8(0.3)$

1 year

$0.8(0.2)$

$1.0(0.2)$

$0.8(0.1)$

Percent $\Delta$

$-4.6(13.8)$

Cycle ergometry endurance $(\mathrm{min})$

Baseline $\quad 5.8(2.3)$

1 year $\quad 12.7(13.5)$

$\begin{array}{ccc}\text { Absolute } \Delta & 6.8(12.8) & 2.6(8.7 \\ \text { Borg scale: post-testing (cycle ergometry): dyspnoea }\end{array}$

$-19.1(18.8)$

$4.2(2.1)$

$6.9(8.3)$

$\begin{array}{ccc}\text { Absolute } \Delta & 6.8(12.8) & 2.6(8.7 \\ \text { Borg scale: post-testing (cycle ergometry): dyspnoea }\end{array}$

\begin{tabular}{|c|c|c|c|c|}
\hline Baseline & $4.4(1.6)$ & $6.1(1.3)$ & $5.2(1.7)$ & 0.023 \\
\hline 1 year & $4.1(2.0)$ & $5.3(1.8)$ & $4.6(1.9)$ & 0.223 \\
\hline Absolute $\Delta$ & $-0.3(2.0)$ & $-0.9(2.0)$ & $-0.6(2.0)$ & 0.556 \\
\hline \multicolumn{5}{|l|}{ mMRC scale } \\
\hline Baseline & $1.0(1.3)$ & $1.2(1.1)$ & $1.1(1.1)$ & 0.788 \\
\hline 1 year & $0.3(0.5)$ & $1.8(1.3)$ & $1.0(1.2)$ & 0.031 \\
\hline Absolute $\Delta$ & $-0.7(0.8)$ & $0.6(1.3)$ & $-0.1(1.2)$ & 0.085 \\
\hline \multicolumn{5}{|c|}{6 min walk test (metres) } \\
\hline Baseline & $388.1(82.8)$ & 425.4 (74.7) & $406.8(79.1)$ & 0.304 \\
\hline 1 year & $412.3(51.7)$ & $416.1(120.0$ & $414.2(89.9)$ & 0.928 \\
\hline Absolute $\Delta$ & $24.2(45.6)$ & $-9.3(70.6)$ & $7.5(60.4)$ & 0.224 \\
\hline \multicolumn{5}{|c|}{ SGRQ-C: total score } \\
\hline Baseline & $53.2(14.1)$ & $57.9(17.9)$ & $55.4(15.6)$ & 0.575 \\
\hline 1 year & 42.1 (12.) & $57.1(21.8)$ & $49.1(18.4)$ & 0.120 \\
\hline Absolute $\Delta$ & $-11.1(9.1)$ & $-0.9(8.6)$ & $-6.3(10.1)$ & 0.045 \\
\hline \multicolumn{5}{|l|}{ CCQ: total score } \\
\hline Baseline & $2.8(1.0)$ & $2.63(1.0)$ & $2.7(1.0)$ & 0.732 \\
\hline 1 year & $2.2(1.0)$ & $2.77(1.0)$ & $2.4(1.0)$ & 0.230 \\
\hline Absolute $\Delta$ & $-0.6(0.8)$ & $0.14(0.7)$ & $-0.3(0.8)$ & 0.051 \\
\hline
\end{tabular}

Data are mean (SD) unless stated otherwise.

SGRQ, St. George's Respiratory Questionnaire (COPD specific); CCQ, clinical COPD questionnaire; mMRC, Modified Medical Research Council dyspnoea scale. p Values are for comparisons between cohorts.
Study results for exercise endurance and HRQL (figure 6) show improvement from baseline for endurance cycle ergometry was $6.8 \pm 12.8$ vs $2.6 \pm 8.7 \min (p=0.277)$ at 1 year. A significant difference was observed in HRQL as assessed by the SGRQ:
$-11.1 \pm 9.1$ vs $-0.9 \pm 8.6(\mathrm{p}=0.044)$ in the $20 \mathrm{~W}$ and $15 \mathrm{~W}$ cohorts, respectively.

At 90, 180 and 365 days, the effect on FEV $_{1}$ of TLD therapy plus $80 \mu \mathrm{g}$ ipratropium bromide at peak was assessed. As illustrated in figure 7, the combination therapy might result in an increase in $\mathrm{FEV}_{1}$ over those seen with an inhaled anticholinergic drug alone. Significant differences between TLD + drug vs TLD alone were seen at each matching time points assessed for both energy cohorts.

\section{DISCUSSION}

This first-in-human clinical trial evaluated the novel TLD therapy, designed to ablate the parasympathetic pulmonary nerves surrounding the main bronchi, thereby decreasing bronchomotor tone in patients with COPD. As a feasibility evaluation, this study included a drug 'wash-out' period to establish baseline values in order to understand the effect of this new therapy alone. This study demonstrated TLD to be feasible, safe and well tolerated. The primary endpoint was met in 95\% of patients, and technical feasibility was 93\%. A tendency toward improvements in lung function, exercise capacity, and HRQL were observed in the $20 \mathrm{~W}$ cohort with statistical significance achieved for $\mathrm{FVC}$ at 90 days $(\mathrm{p}=0.016)$ and 270 days $(p=0.036)$; cycle endurance at 180 days $(p=0.03)$ and SGRQ at 90 days $(\mathrm{p}=0.042), \quad 180$ days $\quad(\mathrm{p}=0.019), 270$ days $(p=0.008)$ and 1 year $(p=0.011)$. These improvements tended to be larger than those seen in the $15 \mathrm{~W}$ cohort with statistically significant difference in SGRQ at 1 year $(p=0.044)$. Additionally, early data suggest an additive effect when TLD is combined with inhaled anticholinergic drugs.

Three procedural adjustments were made during the study in response to asymptomatic airway wall effects observed in three of 12 patients in the $20 \mathrm{~W}$ group. These effects were postulated to be attributable to a combination of energy delivery to the thin, thermally sensitive tissue of the main carina, imperfect balloon contact that limited surface cooling and, potentially, the higher energy level. Subsequent computer modelling and bench testing confirmed heat accumulation in the thin tissue of the carina, and post hoc analysis of procedural imaging indicated the balloon was not able to accommodate itself to sharply tapering or sudden geometric changes of the airway. As a result, the procedure was modified to more distal electrode placement away from the main carina, more detailed visual assessment of balloon contact before activation, and decrease in overall power to $15 \mathrm{~W}$ to further reduce the potential for undesired airway wall effects.

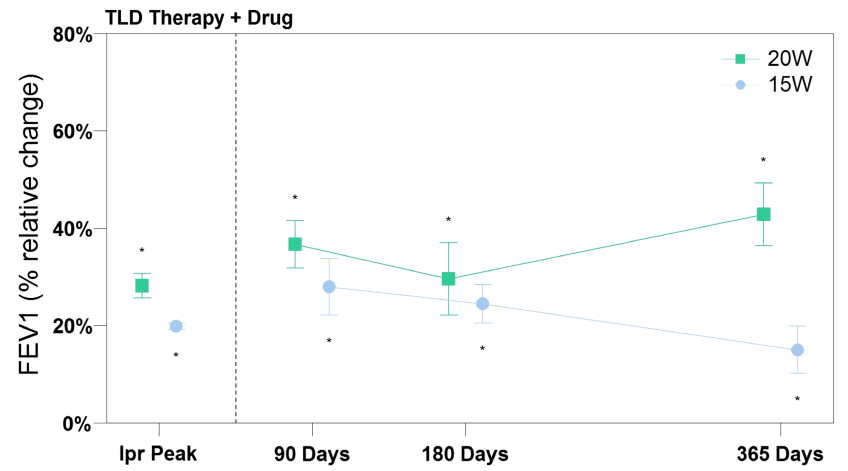

Figure 7 Efficacy measures of targeted lung denervation (TLD) therapy +inhaled ipratropium bromide. Data represented as mean. Error bars represent SEM. * $p<0.05$ compared with baseline. Follow-up data points were compared with results of TLD alone, and all were statistically significant. 
In this study, the 12 patients treated with $20 \mathrm{~W}$ tended to have greater changes from baseline in spirometry, exercise capacity and HRQL, when compared with the 10 patients treated with $15 \mathrm{~W}$. The added effect in the $20 \mathrm{~W}$ group might be attributable to more effective denervation due to a deeper tissue effect at higher energy. On the other hand, the $20 \mathrm{~W}$ group patients were slightly more reversible to ipratropium at baseline, which theoretically, might mean that these patients are more sensitive to TLD therapy. However, we found no difference between the two groups in tiotropium through $\mathrm{FEV}_{1}$ levels. Apart from the airway effects observed, safety profiles for the two energy levels were similar. This might imply that future catheter designs that better accommodate human airway irregularities will ensure better surface cooling and, thus, allow higher energy levels to be used.

In this paper, we introduced TLD, a novel bronchoscopic treatment concept for symptomatic patients suffering from COPD. Based on the concept of ablating parasympathetic pulmonary nerves, TLD was shown to be feasible, safe and well tolerated. TLD has the potential to overcome many of the limitations of inhaled drugs for the treatment of COPD. First, TLD may eliminate inhaler compliance issues for the $63 \%$ of new tiotropium users who discontinue treatment after 1 year. ${ }^{23}$ Second, TLD would not be subject to the peak and trough variations seen with drugs. ${ }^{24}$ Third, TLD may eliminate variable regional drug delivery and deposition in patients with obstructive lung disease $\mathrm{s}^{25}$ by ablating the nerves that travel throughout the bronchial tree independent of regional airflow obstruction. Fourth, by interfering with parasympathetic nerve-derived acetylcholine by two different mechanisms, the combination of TLD +inhaled anticholinergic drugs, as suggested in figure 7 , may have a synergistic effect that results in a reduction in airway obstruction and mucus production, as well as inhibition of local airway inflammation induced by non-neural muscarinic action. ${ }^{8}{ }^{26}$ Further investigation and progressive product development of this novel therapy is warranted, with focus on further refining energy delivery to ablate the nerves and optimise patient selection.

Acknowledgements We would like to thank the investigators, their staff and teams, and the patients who consented to be part of this investigation. We acknowledge the work of the late Prof $C$ Bolliger for his important contributions to this work, and to the field of pulmonary medicine.

Collaborators Panorama Medi Clinic \& University of Stellenbosch, Cape Town South Africa (Ethics Committee reference \# M11/05/013): Chris Bolliger Coenraad Koegelenberg, Johan Theron, Firdows Noor, Elvis Irusen, Dorothy Steyn; University of Groningen, Groningen, The Netherlands (Ethics Committee reference \# NL36608.042.11): Dirk-Jan Slebos, Nick Ten Hacken, Karin Klooster.

Contributors D-JS, KK, CFNK, JT, DS and CTB recruited and treated patients in this trial. MM is the inventor of the lung denervation system. AV was involved in data analysis and data interpretation. All authors helped to write the report. The corresponding author had full access to all data in the study and had final responsibility for the decision to submit it for publication.

Funding Holaira, Inc., Minneapolis, Minnesota, USA.

Competing interests All clinical trial expenses were reimbursed by the study sponsor (Holaira, Inc.). D-JS is the overall study principal investigator. AV is the principle investigator of a second study conducted by the sponsor. MM is founder and chief technology officer of the study sponsor.

Ethics approval The medical ethics committees of the study sites involved, in South Africa and in The Netherlands.

Provenance and peer review Not commissioned; internally peer reviewed.
Open Access This is an Open Access article distributed in accordance with the Creative Commons Attribution Non Commercial (CC BY-NC 4.0) license, which permits others to distribute, remix, adapt, build upon this work non-commercially, and license their derivative works on different terms, provided the original work is properly cited and the use is non-commercial. See: http://creativecommons.org/ licenses/by-nc/4.0/

\section{REFERENCES}

1 Canning B. Reflex regulation of airway smooth muscle tone. J App/ Physiol 2006;101:971-85.

2 Belmonte K. Cholinergic pathways in the lungs and anticholinergic therapy for chronic obstructive pulmonary disease. Proc Am Thor Soc 2005;2:297-305.

3 Pera T, Zuidhof A, Valadas J, et al. Tiotropium inhibits pulmonary inflammation and remodeling in a guinea pig model of COPD. Eur Respir J 2011;38:789-96.

4 Klassen KD, Morton DR. The effect of vagus section on the cough reflex, bronchial caliber, and clearance of bronchial secretions. Surgery 1951;29:483-90.

5 Jammes $Y$, Mei N. Assessment of the pulmonary origin of bronchoconstrictor vagal tone. J Physiol 1979;291:305-16.

6 Abbott OA, Hopkins WA, Van Fleit WE, et al. A new approach to pulmonary emphysema. Thorax 1953;8:116-31.

7 Dimitrov-Szokodi D, Husveti A, Balogh G. Lung Denervation in the Therapy of Intractable Bronchial Asthma. J Thoracic Surg 1957;33:166-84.

8 Gosens R, Zaagsma J, Meurs $\mathrm{H}$, et al. Muscarinic receptor signaling in the pathophysiology of asthma and COPD. Respir Res 2006;7:73.

9 Vincken W, van Noord JA, Greefhorst APM. Improved health outcomes in patients with COPD during 1 yr's treatment with tiotropium. Eur Respir J 2002:19:209-16.

10 Tashkin DP, Celli B, Decramer M, et al. Bronchodilator responsiveness in patients with COPD. Eur Respir J 2008;31:742-50.

11 Tashkin DP, Celli B, Senn S, et al. A 4-year trial of tiotropium in chonic obstructive pulmonary disease. NEJM 2008;359:1543-54.

12 Maltais F, Hamilton A, Marciniuk D, et al. Improvements in symptom-limited exercise performance over $8 \mathrm{~h}$ with once-daily tiotropium in patients with COPD. Chest 2005;128;1168-78.

13 Global Strategy for the Diagnosis, Management and Prevention of COPD. 2014 [http://www.goldcopd.org]

14 Qaseem A, Wilt T, Weinberger $S$, et al. Diagnosis and management of stable chronic obstructive pulmonary disease: a clinical practice Guideline update from the ACP, ACCP, ATS and ERS. Ann intern Med 2011;155:179-91.

15 Meguro M, Barley E, Spencer S, et al. Development and Validation of an Improved, COPD-Specific Version of the St. George Respiratory Questionnaire. CHEST 2007:132:456-63.

16 Van der Molen T, Willemse B, Schokker S, et al. Development, validity and responsiveness of the Clinical COPD Questionnaire. Health Qual Life Outcomes 2003;1:13.

17 Bestall JC, Paul EA, Garrod R, et al. Usefulness of the Medical Research Council (MRC) dyspnea scale as a measure of disability in patients with chronic obstructive pulmonary disease. Thorax 1999;54:581-6.

18 Maltais F, Hamilton A, Marciniuk D, et al. Improvement in Symptom-Limited Exercise Performance over $8 \mathrm{~h}$ With Once-Daily Tiotropium in Patients with COPD. Chest 2005:128:1168-78.

19 Miller M, Hankinson J, Brusasco V, et al. Series "ATS/ERS Task Force: Standardization of Lung Function Testing". Eur Respir J 2005;26:319-38.

20 Wagner J, Clausen J, Coates A, et al. Series "ATS/ERS Task Force: Standardization of Lung Function Testing". Eur Respir J 2005;26:511-22.

21 Weisman IM, Beck KC, Casaburi R, et al. ATS/ACCP statement on cardiopulmonary exercise testing. Am J Respir Crit Care Med 2003;167:211-77.

22 ATS Committee on Proficiency Standards for Clinical Pulmonary Function Laboratories. ATS statement: guidelines for the six-minute walk test. Am J Respir Crit Care Med 2002;166:111-7

23 Breekveldt-Postma NS, Koerselmana J, Erkensa JA, et al. Enhanced persistence with tiotropium compared with other respiratory drugs in COPD. Respir Med 2007:101:1398-405.

24 Maesen FPV, Smeets JJ, Sledsens TJH, et al. Iprotropium bromide, a new long-acting antimuscarinic bronchodilator: a pharmacodynamic study in patients with chronic obstructive pulmonary disease (COPD). Eur Respir J 1995;8:1506-13.

25 Anderson P. Use of Respimat Soft Mist Inhaler in COPD patients. Int J Chron Obstruct Pulmon Dis 2006;1:251-9.

26 Profita M, Albano GD, Riccobono L, et al. Increased levels of Th17 cells are associated with non-neuronal acetylcholine in COPD patients. Immunobiology 2014:219:392-401. 